\title{
Meiosis in a polyhaploid twin plant and a hexaploid hybrid of Valeriana sambucifolia Mikan
}

\author{
M. SKALINSKA \\ Institute of Plant Anatomy and Cytology, University of Kraków
}

(entered: 15.XII.53 r.)

\section{ORIGIN AND MORPHOLOGY OF THE TWIN-PLANTS}

A pair of twins has been found among seedlings of Valeriana sambucifolia Mikan germinated in the laboratory in 1950. The mother-plant, $V$. sambucifolia $(2 \mathrm{n}=56)$ originated from the northern slope of Giewont in the Tatra Mts. This plant (Field N. 229, S k a 1 i n s k a, 1951) has been transplanted from its natural habitat in July 1948 into the experimental field of the Institute of Plant Anatomy and Cytology and flowered there in 1949. Seeds developed after open pollination were harvested and sown on the 15th March 1950 on Petri dishes in the laboratory. Most seeds germinated after 7 to 10 days. From one of these seeds a pair of twins of distinctly unequal size developed; the smaller partner appeared on the eighth day, the larger - two days later. The smaller plant represented a polyhaploid $(2 \mathrm{n}=28)$ whereas the larger seedling proved to be a hexaploid $(2 \mathrm{n}=42)$ evidently representing a cross-product of $V$. sambucifolia with a tetraploid plant. In Valeriana neither twins nor hybrids between different chromosomic types have been described hitherto; thus, the plants deserved a more detailed study.

Studies in twins of various plant genera have shown that in numerous instances the partners may be almost identical; sometimes however they may manifest distinct differences both in respect of morphology and of chromosome numbers (M ü n t z in g, 1937, $\mathrm{S} k$ o v s t e d, 1939). The twin plants of Valeriana manifested a high degree of dissimilarity since the first stages of their development. As it has been already mentioned, the smaller twin plant has been more precocious at germination. This seedling had a tiny rootlet of c. $2 \mathrm{~mm}$. and a single very small cotyledon; a growing point however was not yet formed at this stage. On the other 
hand, the larger seedling seemed to be normally developed: it had two cotyledons and a stouter rootlet. A few days after germination the two plants labelled $A$ (the larger seedling) and $B$ (the smaller seedling) were planted into separate pots in light soil; they were kept under glass jars in the first period of their development.

Twin plant A. Primarily this plant was regarded as the ,normal“" partner in the pair of twins, representing a true sambucifolia type, like its mother plant. It soon became evident however that in spite of its nearly normal appearance this plant does not equal in respect of the speed of development the fast-growing sambucifolia plants from the same sample of seeds. After two months its leaves still remained small, sharply contrasting with the abundantly developed foliage of the true sambucifolia seedlings. The examination of root-tip mitoses has proved that this plant was a hexaploid with 42 somatic chromosomes (Fig. 1, 15), thus, it represented a chromosomic type unknown previously in Valeriana. Therefore this plant was given special care. In view of its delayed and somewhat defective growth it was kept in a greenhouse during the winter, since it was probable that it would not survive the conditions of the experimental field. The plant however failed to flower in two successive years 1951 and 1952 and died in late summer of that year.

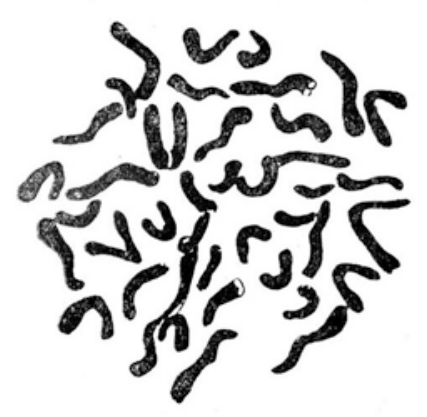

1

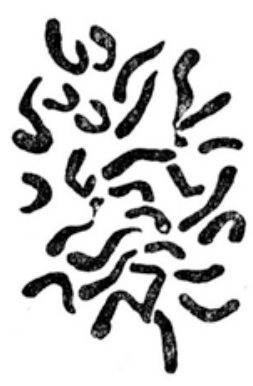

2

Fig. 1, 2 - Somatic metaphases from root tips of the twin plants of Valeriana sambucifolia; 1 - the hexaploid twin plant A, 2 - the polyhaploid twin plant B. (the same plates as in Fig. 15 and 16) ( $\times 3100)$.

As far as the origin of this plant is concerned, presumably it has arisen from a spontaneous cross in the experimental field. In 1949 many specimens of Valeriana species brought from natural habitats were growing there. Among these specimens a tetraploid strain of $V$. exaltata (Field N. 225, cf. S k a $1 \mathrm{i}$ n s k a, 1951) was growing in the vicinity of the sambucifolia mother plant. The partial overlapping of its flowering time 
with that of the strictly allogamous species $V$. sambucifolia favoured a spontaneous cross-pollination by insects. It should be added that attempts at obtaining hybrids between octoploid and tetraploid types of Valeriana were done by the author repeatedly since 1945 but without any success. Artificial crosses failed altogether or led to the production of unviable embryos ( $\mathrm{S} \mathrm{k}$ a $1 \mathrm{i}$ n s k a 1947 and unpublished). The occurrence of a plant with 42 chromosomes proves however that in rare instances such a hexaploid type is able to develop.

Twin plant B. In the first stages the development of this plant was notably delayed, before a growing point has become differentiated. Later on, very small leaves were formed and, after overcoming the difficulties of the early stages of development, the plant begun to grow more normally, although it maintained its dwarf habit. Two months after germination - in the end of May - a few root tips could be fixed and in June the plant has been transplanted into the experimental field. It flowered in May 1951 and perished soon afterwards. This plant was totally sterile. Before the expansion of its flowers a part of its flower buds has been fixed for the study of meioses in PMC's and of later stages of pollen development.

Morphologically, the smaller twin plant represented a dwarfed specimen of $V$. sambucifolia. The comparison of the height of this twin plant with that of flowering plants from the same sample of seeds permit to establish a notable difference; normal sambucifolia-plants attained in the experimental field the height of c. $100 \mathrm{~cm}$ whereas the flowering stem of plant B was only $30 \mathrm{~cm}$ high and its inflorescence was poorly developed. On the other hand, in respect of other features this plant represented a true $V$. sambucifolia: as well known, V. sambucifolia develops overground runners which are organs of vegetative propagation; runners 10 to $15 \mathrm{~cm}$ long were present also in the polyhaploid plant. The lower stem leaves (about $5 \mathrm{~cm}$ long) had 3 pairs of slightly toothed lateral leaflets, and the upper ones ( 3 to $4 \mathrm{~cm}$ long) usually two pairs only. The low number of lateral leaflets in stem leaves is one of the features by which $V$. sambucifolia may be easily identified and distinguished from any other Valeriana species. A third character of $V$. sambucifolia, namely the early flowering, should be also mentioned; in 1951 the polyhaploid plant flowered in the half of May, simultaneously with normal sambucifolia plants. The above details show that the twin plan B really does represent a dwarfed $V$. sambucifolia. The chromosome number of this plant $(2 \mathrm{n}=28)$ established on root tip mitoses (Fig. 2, 16) permits to assume that the plant developed from a synergid, thus it represented a polyhaploid type of the octoploid $V$. sambucifolia. 


\section{A SECOND HEXAPLOID HYBRID}

In view of the fact that a hexaploid hybrid has been found among the seedlings of $V$. sambucifolia as the larger member of a twin pair, the possibility of the occurrence of other plants of the same type has been taken into consideration. Therefore, a detailed morphological examination of the remaining plants from the same lot has been undertaken during their flowering season in summer 1951. As a result of this study a single aberrant plant has been detected among the progeny of $\mathrm{V}$. sambucifolia. The cytological investigation of this plant carried out on meioses in P.M.C's has proved that it represented a second hexaploid hybrid. The finding of this plant compensated partially the loss of the twin plant A which represented the same chromosomic type but perished before flowering.

It seems probable that the twin plant $\mathrm{A}$ and the second hexaploid (Field N. 229/3) have arisen from the same cross-pollination by insects. The mother plant developed in 1949 a single inflorescence; its first fruits have been dispersed by the wind and only the last achenes (in the number of 17) were harvested. This detail is of importance in view of the fact that in the experimental field the second half of the flowering period of $V$. sambucifolia overlaps the beginning of flowering of the tetraploid strain of $V$. exaltata. The seeds which gave the hexaploid hybrids developed and ripened simultaneously.

Morphologically, plant $229 / 3$ was intermediate between the mother species $V$. sambucifolia and the putative pollen parent $V$. exaltata. Short overground runners were present. (The same is true of the hexaploid twin plant). The lower stem leaves had 6 pairs of slightly toothed lateral leaflets while the upper ones had 5 pairs. These numbers are intermediate between those of $V$. sambucifolia whose stem leaves bear only 3-4 pairs, and those of $V$. exaltata (tetraploid strain, Field N. 225) with $7-8$ pairs. The flowering stem of the hexaploid plant however was shorter than that of the very vigorous mother plant and of the still taller plants of the tetraploid strain of $V$. exaltata. Possibly the vigour of this plant was somewhat affected. It should be added that it was totally sterile and it did not survive the second winter season.

\section{THE ANTHERS}

The course of meiosis in P.M.C's has been studied in the polyhaploid twin plant $\mathrm{B}$, as well as in the hexaploid hybrid $229 / 3$ probably corresponding to twin plant $\mathrm{A}$ in respect of its karyological structure.

Flower buds of these two plants have been fixed in May, 1951. The fixation has been done, during the author's serious illness, by $\mathrm{Dr}$ 
H. W c i s $ł$ o, research worker in the Institute; her excellent help is greatly appreciated by the author. Of the fixatives used, the best results were obtained with the $\mathrm{N}$ a v a $\mathrm{s} h$ i n's fixative diluted with an equal part of distilled water (according to $M$ a $n t o n, 1942)$. In addition, in spring 1952 buds of one plant of the tetraploid strain of $V$. exaltata have been fixed for comparison with the obviously abnormal tetraploid twin plant B. The microtome sections 10 to $13 \mu$ thick, were stained with Newton's gentian violet.

In Valeriana species on transversal sections of normally developed young buds in the anthers groups of P.M.C's are visible usually arranged in bowshaped rows. In early prophase, they form a rather compact tissue, uniformly filling the space between the layers of the tapetal cells. At metaphase, owing to the growth of the anthers they lie separate after having rounded up. In post-meiotic stages the anthers' size increases considerably.

Of the two plants studied, the hexaploid hybrid $229 / 3 \mathrm{had}$, on the whole, normally developed anthers, whereas the flower buds of the polyhaploid plant seemed to have a defective development. In order to estimate the deviations from a normal development occurring in this plant, a detailed comparison of buds and anthers of the tetraploid twin plant B with those of a normal tetraploid plant ( $V$. exaltata, field N. 225) has been carried out at various stages. In order to ascertain the dimensions of the floral parts at different stages of development, measurements have been done under the microscope with the aid of an eyepiece micrometer scale. The measurements concerned the diameter of the flower buds at prophase of meiosis (pachytene) and at later stages, the diameter of the pollen sacs in the corresponding stages and the size of the P.M.C's.

At pachytene, the diameter of a bud of the polyhaploid twin plant $B$ hardly attains $0.5 \mathrm{~mm}$ while in the normal tetraploid plant 225 it is larger, the respective value being $0.7 \mathrm{~mm}$. This last value however corresponds to a later stage in the polyhaploid; in flower buds of this size the degeneration of the pollen grains already sets in.

The diameter of the pollen sacs was measured together with the tapetal layer on transversal sections of the buds. The stages of meiosis ranged from prophase (pachytene) to the tetrad stage. Also some postmeiotic stages have been taken into consideration. The differences between the two plants are considerable. At pachytene the respective values are: for the polyhaploid $57 \mu$ only, while for $V$. exaltata $-96 \mu$; at interkinesis the diameter is $72 \mu$ in the first plant and $112 \mu$ in the second. Thus, in this stage the pollen sacs of the polyhaploid attain hardly $2 / 3$ of the normal width. The value found at pachytene in $V$. exaltata corresponds in ${ }^{-t}$ the polyhaploid to a much later stage of bud development in which 
the periplasmodium nuclei are visible among the pollen grains already coated by their exines. Likewise, the value found at interkinesis in $V$. exaltata corresponds to a still later post-meiotic stage of the polyhaploid with notable size differences of the pollen grains making their appearance (Fig. 23).

It is interesting to note that the diameter of the P.M.C's (measured at I. Metaphase and at Interkinesis along the axis of the spindles) is approximately the same in the two tetraploids (c. $16 \mu$ ). In the polyhaploid however in the more limited space of a loculus the number of P.M.C's is lower than in the normal tetraploid plant. This shows that the number of cell divisions in pre-meiotic stages must have been lower than normal in the imperfectly developed anthers of the polyhaploid plant. Probably in consequence of this defective development, the P.M.C's are crowded in the narrow space available and frequently they fail to round up. The intense growth following tetrad formation in anthers of normal plants is in sharp contrast to the conditions, observed in the polyhaploid, the growth of the anthers is notably delayed and degeneration of most pollen grains sets in short time later (Fig. 24).

On the other hand, in the hexaploid hybrid 229/3 the development of the floral organs was approximately normal. The anthers were notably larger than in the polyhaploid twin plant B; their normally occurring elongation resulted in a looser arrangement of the P.M.C's and rendered possible their rounding up at late prophase.

\section{MEIOSIS}

A. Th e hex a ploid hy b r i d. The course of meiosis in P.M.C's of this plant was quite normal. Pairing was complete or almost complete. The most frequent configurations occurring at I. Metaphase were represented by 21 bivalents or 20 bivalents and 2 univalents (Fig. 3 , 4). Polyvalents were not formed. The bivalents with one terminal chiasma form a regular equatorial plate (Fig. 17, 18). Details of I. Metaphase and Anaphase could be studied easily owing to a very good fixation of the respective stages. The spindles were relatively broad and the paired chromosomes were less crowded than those of the polyhaploid twin plant in the respective stages. At I. Anaphase the two plates in polar view show a regular distribution of 21 chromosomes to each pole (Fig. 5). The chromosomes manifest distinct size differences: large and smaller chromosomes could be easily distinguished. These size differences correspond to the differentiation in the somatic set (Fig. 1, 15) in which longer and shorter chromosomes are visible. The I. Telophase is perfectly normal, without lagging chromosomes. At Interkinesis two daughter nuclei with the reduced chromosome number are formed; interkinesis seems to be 
a stage of a relatively long duration; this stage is suitable for counting the chromosomes in view of the fact that they retain their stain-ability. The number 21 was invariably found on the poles (Fig. 6). The homoeo-


Fig. 3-7. Meiosis in the hexaploid hybrid 229/3; 3 - I Metaphase (21 bivalents); 4 - I Metaphase (20 bivalents and 2 univalents); 5 - two plates of I Anaphase with 21 chromosomes the plain chromosome in the lower plate was found in the preceding. section; its position in the plate is approximate). ( $\times 3100) .6$ - Interkinesis, 21 chromosomes on each pole; 7 - a normal tetrad and two primary pollen grains $(\times 1500)$.

typic division, likewise, has a normal course. The tetrad formation occurs in the usual way; the cell walls delimiting the four microspores arise presumably by furrowing. In early stages of pollen development distur- 
bances were not observable (Fig. 7). The exine was well formed (Fig. 25). Later stages of pollen development have been studied on acetocarmine smears. In older buds, short before the expansion of the flowers, the pollen grains had a very uniform appearance in respect of their size; however, in spite of the very regular course of meiosis and of later stages of development they were unviable. Most pollen grains were still uninucleate at this stage; all were imperfectly filled, their protoplast showing distinct signs of abortion.

B. The te traploid tw i $\mathrm{n}$ pl a $\mathrm{nt}$ B. In spite of the defective development of the anthers, this plant had on the whole a surprisingly regular course of meiosis. The chromosome pairing was complete or almost complete. At I. Metaphase up to 14 bivalents could be discerned. In the majority of the P.M.C's the congression of the bivalents was normal; in the I. Metaphase spindle they were arranged in a rather regular equatorial plate (Fig. 8, 20), usually however they were crowded in the relatively narrow spindle. Only occasionally the appearance of the equatorial plate was somewhat irregular, with unorientated bivalents and two or four univalents lying off the spindle (Fig. 9, 21). The separation of the paired chromosomes at I. Anaphase and their distribution to the poles had a normal course in most cells. Accordingly, at I. Telophase 14 chromosomes may be counted easily on each pole (Fig. 11, 22). At Interkinesis the great majority of the cells showed a quite regular distribution (14-14) (Fig. 13).

Disturbances during the first meiotic division were rather rare; they consisted in some instances in a delayed separation of some pairs which at I. Telophase persisted between the two groups of chromosomes already on the poles (Fig. 10). An abnormal telophase of this type was observed in a loculus with the majority of the P.M.C's at interkinesis. In the vicinity of this cell two other abnormal P.M.C's have been found; one of these cells contained a restitution nucleus with 28 chromosomes, while in the second presumably a somewhat earlier stage of formation of a restitution nucleus could be observed (Fig. 12). A further rare deviation from a normal development consisted in an unsynchroneous progress of meiosis in P.M.C's occurring in the same pollen sac. In a normal development all P.M.C's in a loculus are at the same stage or show a gradual transition to a later stage from the bottom to the top of a pollen sac. One of the abnormalities observed was the occurrence of single P.M.C's at earlier stages irregularly dispersed among cells representing a more advanced stage; e. g., among P.M.C's at Interkinesis sometimes cells at I. Metaphase, thus notably delayed in their development could be found in some loculi.

The homoeotypic division had also on the whole a normal course. Occasionally one single spindle, probably from restitution, could be ob- 
served. Some minor disturbances (chiefly single chromosomes left outside the II. Metaphase spidles) rarely occurred. The most important irregularities started at the time of tetrad formation. They consisted in a defective development of the cell walls delimiting the four microspores. As a result, besides the normal one-nucleate microspores, also larger cells
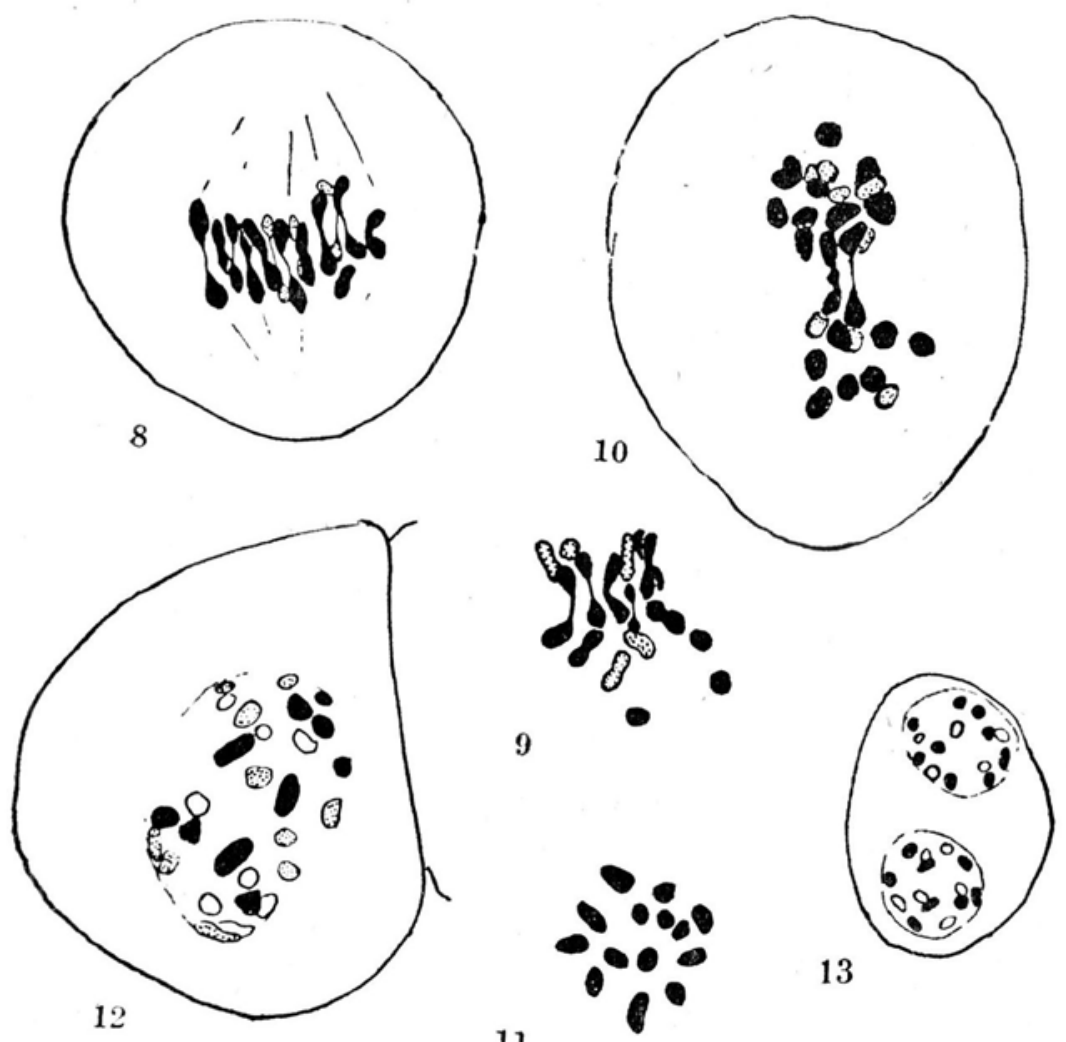

Fig. 8-13. Meiosis in the polyhaploid twin plant B. 8 - I Metaphase (14 bivalents); 9 - I Metaphase (12 bivalents and 4 univalents) (the same as in Fig. 21 on the left; in Fig. 9 the chromosomes are slightly spaced for clarity); 10 - abnormal I Telophase with connections persisting between two bivalents and uneven chromosome distribution to the poles $(12-16) ; 11$ - I Telophase (one pole) 14 chromosomes; 12 probable formation of a restitution nucleus at interkinesis; 13 - normal interkinesis with 14 chromosomes on each pole. $(8-12 \times 3100 ; 13-1500 \times)$.

with two or three nuclei appeared at the tetrad stage (Fig. 14). Owing to the imperfect growth of the anthers, the P.M.C's were found at this stage unusually crowded in the narrow space of the loculi; vivid divisions start in this period in the tapetal cells; their intense growth, preceding the formation of the periplasmodium, contributed evidently to this strong 
crowding of the P.M.C's and of microspores partly freed already of the membranes of their mother cells. In these conditions a strong competition seems to occur between the developing microspores which undergo a very irregular further development. Notable size differences appear at that time (Fig. 23). The largest - chiefly two- and three-nucleate cells con-

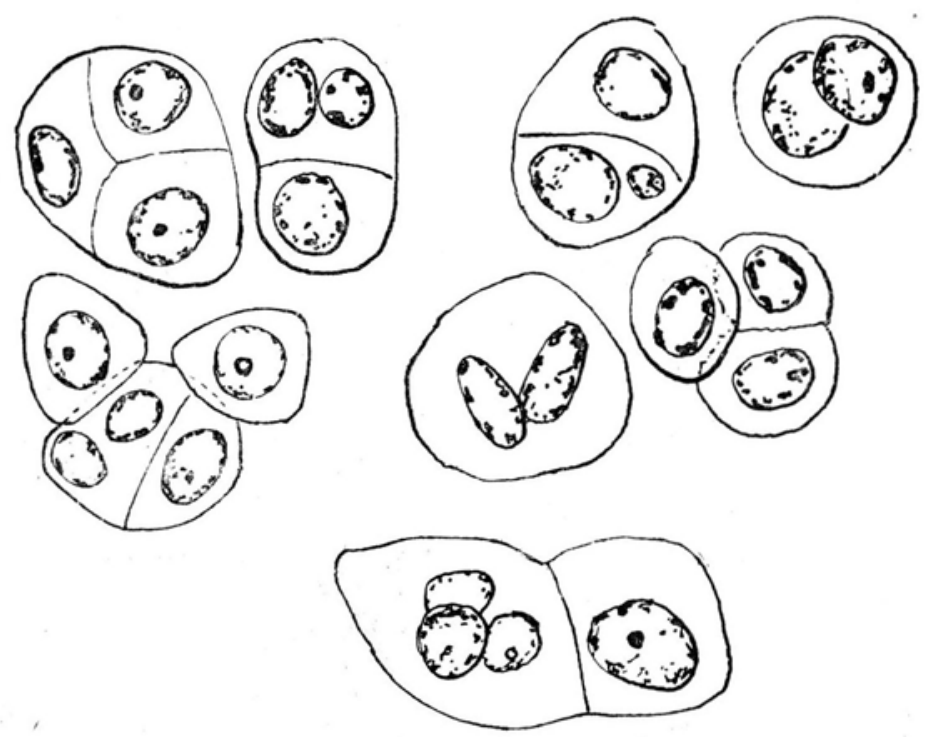

Fig. 14. Abnormal tetrads and primary pollen grains of the polyhaploid twin plant B. Note the bi- and trinucleate cells. $(\times 1500)$.

tinue their development while the majority of the uni-nucleate microspores gradually degenerate. Their abortion begins soon after the penetration of the periplasmodium among the microspores. In later stages they are almost completely devoid of their living contents; their exines, already formed are shrunken and wrinkled. On the other hand, the larger, chiefly bi- or tri-nucleate primary pollen grains continue for a time their development. Their size increases enormously (Fig. 24). Ultimately these giant grains also degenerate. The striking size differences among the pollen grains are maintained after their abortion. In a pollen sac usually only a few giant grains are formed; they are surrounded by strongly wrinkled entirely empty small grains.

\section{DISCUSSION}

In most polyhaploids studied hitherto asyndesis has been observed at meiosis; only occasionally a few bivalents appeared in addition to the univalents (e. g. Triticum compactum, G a i n e s and A a s e, 1926; 
Nicotiana Tabacum, C h i p m a n and Goods p e ed, 1927; L a m$\mathrm{m}$ e $\mathrm{r} \mathrm{t} \mathrm{s}$, 1934). This behaviour may be regarded as the consequence of allopolyploidy of the parent species of the respective polyhaploids. In rare instances however a high degree of regularity could be observed in chromosome pairing of polyhaploid organisms; a polyhaploid member of a pair of twins which appeared in the progeny of a tetraploid Solanum hybrid ( $S$. chaucha $\times S$. tuberosum) has been described by $\mathrm{L}$ a $\mathrm{m} \mathrm{m}$ (1938). At meiosis this polyhaploid formed 12 bivalents. Likewise, a polyhaploid plant which appeared spontaneously in a 72-chromosomic strain of Poa pratensis (M ü n t z i n g, 1940) had a normal chromosome pairing in $76^{\%} \%$ of the P.M.C.'s studied. The formation of 18 bivalents in this polyhaploid is the more interesting as $P$. pratensis is considered an allopolyploid species; this assumption expressed by $\mathrm{M}$ ü $\mathrm{n} \mathrm{t} \mathrm{z} \mathrm{i} \mathrm{n} \mathrm{g} \mathrm{is} \mathrm{sup-}$ ported by the observations of $\mathrm{K}$ i e $1 \mathrm{l}$ a $\mathrm{n} \mathrm{d} \mathrm{e} \mathrm{r} \mathrm{(1942)} \mathrm{on} \mathrm{a} \mathrm{sub-haploid}$ plant of this species which appeared as a member of a triplet set. The sub-haploid plant $(2 \mathrm{n}=18)$ manifested a well marked similarity to Poa trivialis L., thus, according to this author it may be assumed that Poa trivialis is one of the species which have contributed to the formation of Poa pratensis (p. 219).

A fertile polyhaploid plant of Bromus inermis L e y s s. studied by E $11 \mathrm{i} \mathrm{o} \mathrm{t} \mathrm{t} \mathrm{and} \mathrm{W} \mathrm{i} 1 \mathrm{~s}$ i e (1948) deserves special mention. This plant $(2 \mathrm{n}=28)$ formed at meiosis in P.M.C's not only bivalents but also some polyvalents and the chromosome distribution at I. Anaphase was quite regular. A further example of a complete chromosome pairing in P.M.C's of a polyhaploid is represented by the twin plant B of Valeriana sambucifolia described in the present paper. Its four chromosome sets were able to form up to 14 bivalents in the way of autosyndesis. This ability of pairing suggests that they are homologous at least to some extent. According to M e u r m a n (1925) however in octoploid conditions $V$. sambucifolia ( $=V$. excelsa Poir.) forms exclusively bivalents at meiosis in P.M.C's. In spite of this it seems to represent a species which has arisen by autopolyploidy. In connection with this it should be added that the putative origin of $V$. sambucifolia has been discussed in a previous paper ( $\mathrm{S} \mathrm{k}$ a $1 \mathrm{i}$ ń s k a, 1951, p. 165). Presumably it represents a northern mountain species possibly derived from an almost extinct diploid ancestral form similar to that described by $\mathrm{R} \mathrm{u} \mathrm{n} \mathrm{q} \mathrm{u} \mathrm{is} \mathrm{t}$ (1937) from the northern shore of the island Svano (Angermanland). The octoploid $V$. sambucifolia $\mathrm{M}$ i $\mathrm{k}$ a $\mathrm{n}$ occurring in mountain regions of Central Europe represents a younger form which could have evolved from that diploid through chromosome doubling achieved in two steps. In natural autopolyploids however usually the chromosome sets are no longer strictly identical. Presumably their differentiation has been attain- 
ed gradually as a result of gene mutations or other changes (D o b z$\mathrm{h} \mathrm{a} \mathrm{n} \mathrm{s} \mathrm{k} \mathrm{y,} \mathrm{1947)} \mathrm{this} \mathrm{contributed} \mathrm{to} \mathrm{a} \mathrm{divergent} \mathrm{evolution} \mathrm{of} \mathrm{their}$ once identical sets. The degree of dissimilarity attained by $V$. sambucifolia however does not affect the mode of pairing in the spontaneously. formed polyhaploid: autosyndetic pairing is complete or almost complete.

The hexaploid hybrid $229 / 3$ represents in respect of its karyological structure the combination of two sets of different origin: 28 chromosomes representing the reduced set of $V$. sambucifolia and introduced into the cross by the normal egg-cell of the mother plant; in addition, 14 chromosomes of the pollen parent, probably $V$. exaltata. It seems probable that also this hybrid has an autosyndetic chromosome conjugation: the four sets derived from $V$. sambucifolia correspond to the somatic chromosome complement of the polyhaploid twin plant; presumably aiso in the hexaploid hybrid they form 14 pairs in the absence of identical mates; it is plausible that the remaining 7 bivalents resulted likewise from an autosyndetic pairing of the chromosomes of the pollen parent.

The putative father plant seems to represent an autotetraploid of a rather recent origin. The morphological features of the hexaploid hybrid (see p. 362) suggest that the pollen parent belonged to a tetraploid strain of $V$. exaltata. According to the author's previous studies, diploid strains of this species prevail in Poland ( $\mathrm{S} \mathrm{k}$ a l i n s k a, 1951). The occurrence of a tetraploid strain native in a single habitat in western Poland gives evidence of a cytological differentiation of this species; the tetraploids have arisen evidently by spontaneous chromosome doubling. Thus, autosyndetic pairing at meiosis in the hexaploid hybrid seems to be more probable than the other possibility, that of allo-autosyndesis: 14 bivalents resulting from inter-specific pairing between exaltata and sambucifolia chromosomes and 7 from intra-specific pairing of two sambucifolia sets.

The two twin plants had a notably lowered vitality and were sterile. In the polyhaploid the lack of vigour manifested itself in its dwarf habit and the defective development of the anthers. As a consequence, the post-meiotic stages were strongly affected; a quite abnormal development preceded the total abortion of the pollen grains (Fig. 24) in spite of a normal course of meiosis in most P.M.C's.

In the hexaploid twin plant $\mathrm{A}$ the four chromosome sets of $\mathrm{V}$. sambucifolia were exactly identical with those of twin plant B; the addition of two sets of the pollen parent must have resulted in an ill-balanced structure unable of a normal development.

The second hexaploid hybrid (229/3) corresponded in general in respect of its cytological structure to twin plant A; it surpassed however this plant by a higher degree of vitality. The development of its vegeta- 
tive parts and of flowers was normal; disturbances started only in relatively late stages of pollen development leading to its abortion.

It seems probable that some factors causing a lowered vitality of the two twin plants and the pollen sterility of the hexaploid hybrid 229/3 are linked with the structure of the mother plant $V$. sambucifolia. In the course of evolution of this polyploid allogamous species some lethals or sublethals may have arisen during the gradually occurring differentiation. In the selfed progeny of some polyploids unviable types (e. g. albino seedlings in Phleum pratense, $\mathrm{N}$ o $\mathrm{r}$ d e $\mathrm{n} \mathrm{s} \mathrm{k} \mathrm{i} \mathrm{ö} 1 \mathrm{~d}, 1953)$, may appear as a consequence of a very complex segregation. In the diploids such deletorious mutations are eliminated by natural selection, whereas in the polyploids the respective factors remain concealed in many generations since recombination by cross pollination prevents their manifestation. However in polyhaploids and in some hybrid structures their deletorious influence, no longer balanced by the normal chromosome complement is able to make its appearance.

Studies in morphological characters of the hexaploid hybrid 229/3 are of importance in connexion with the problem of evolution in the section Officinalis in view of the fact that this hybrid showed a well marked similarity to some British biotypes. The author's previous investigations concerning morphology, cytology, ecology and geographic distribution of Valeriana in Great Britain $(1945,1947)$ and in Poland (1951) contributed to elucidate some evolutionary lines in the section Officinalis of this genus. A more primitive stage of evolution has been attained in Central Europe than in Great Britain. The more primitive stage is expressed by the occurrence of three distinct species sharply delimited both morphologically and cytologically ( $\mathrm{S} \mathrm{k} \mathrm{a} \mathrm{l}$ i ń s k a, 1951). Their distinct separation is in sharp contrast with conditions observed in Great Britain where a range of intergrading forms connects the extremes (S p r a g u e, 1943, T o d d, 1942). In 1947 the author expressed the opinion that the intergrading forms are presumably of hybrid origin, thus, a kind of fusion occurred between the formerly separate groups resulting in the production of a so-called ,hybrid swarm“ (A 11 a n, 1940) or a large polyploid complex representing the polymorphic species Valeriana officinalis s. lato in Great Britain.

An experimental attack of the problem in the way of artificial crossing of the extreme forms was followed by a missuccess; the almost negative results of crosses did not allow to test the validity of the author's assumption concerning the origin of British intergrading forms. However a spontaneous cross between $V$. sambucifolia and a tetraploid strain of $V$. exaltata gave rise to a hybrid plant the morphological features of which roughly correspond to some intermediate British biotypes. The 
presence of overground runners and an increased number of pairs of lateral leaflets observed in this hybrid are frequently combined in plants representing intermediate forms in Great Britain; on the other hand, they do not occur together in plants native in Central Europe. With regard to the number of lateral leaflets in the hexaploid hybrid, this value (5 to 6 pairs) is intermediate between $V$. sambucifolia (3 to 4 pairs) and $V$. exaltata (7 to 8 pairs). The collective species $V$. officinalis shows in this respect a high degree of diversity: the continuous range extends from 3 to 10 pairs; forms with 5 or 6 pairs are most frequent chiefly among octoploids (cf. Table 2, S k a 1 i ń s k a, 1947). Although the hybrid differs from the British forms by its hexaploid chromosome number, its morphological similarity to some intermediate biotypes from the British Isles strongly suggests that they could have arisen by hybridisation. A more exact reconstruction of British biotypes would result from the fertilization of a normal egg-cell of $V$. sambucifolia by an unreduced gamete of a tetraploid strain of $V$. exaltata. Although tetraploid types produce rather frequently unreduced (giant) pollen grains, it is evident that the synthesis of an octoploid hybrid with the part of such grains can be hardly expected as a result of artificial crosses, in view of the considerable difficulties. It may be anticipated however that such unreduced pollen grains would be favoured on the stigma of octoploid plants and would be able to compete successfully with normal grains, like in some other genera (e. g. Aquilegia, S k a 1 i ń s k a, 1937).

\section{SUMMARY}

A pair of dissimilar twins which appeared among seedlings of $\mathrm{Va}$ leriana sambucifolia $\mathrm{M}$ i $\mathrm{k}$ a $\mathrm{n} \quad(2 \mathrm{n}=56)$ represented a very small polyhaploid $(2 \mathrm{n}=28)$ presumably developed from a synergid and a hexaploid hybrid $(2 \mathrm{n}=42)$ which originated from a spontaneous cross probably with a tetraploid $V$. exaltata. In addition in the same group of seedlings a second hexaploid hybrid has been detected. The two twin plants had a notably lowered vitality; the hexaploid sister-plant was more vigorous, it was however totally sterile in spite of a regular course of meiosis. In most P. M. C's 21 bivalents were formed presumably by autosyndesis. A regular meiosis with complete or almost complete chromosome pairing has been observed also in P. M. C's of the polyhaploid twin plant. Disturbances beginning before the formation of tetrads led to a highly abnormal development and to a total pollen sterility.

The author's opinion expressed in 1947 that the British Valeriana officinalis s. lato represents a non-uniform polyploid complex of hybrid origin is supported by the well marked similarity of the spontaneous hybrid to British intergrading forms assigned to that species. 


\section{REFERENCES}

A lle n H. H., 1940, Natural hybridization in relation to taxonomy. The New Systematics. ed. J. S. Huxley, Oxford, $515-528$.

Chipman, R. H. and Goodspeed T. H., 1927. Inheritance in Nicotiana Tabacum. VIII. Cytological features of purpurea haploid. Univ. Calif. Pub. Bot. 11, $141-158$.

Dobzhansky T., 1947. Genetics and the Origin of Species. New York.

Elliott F. C. and Wilsie C. R., 1948. A fertile polyhaploid in Bromus inermis. Journ. of Her., 39, $376-380$.

G a in e s E. P. and A a s e H. C., 1926. A haploid wheat plant. Amer. Journ. Bot. 13. $377-385$.

Kiel 1 a nder C. L., 1942. A subhaploid Poa pratensis L. with 18 chromosomes and its progeny. Svensk Bot. Tidskr. 36, $200-220$.

L. a $\mathrm{m}$ m R., 1938. Notes on a haploid Potato hybrid. Hereditas, 24, 391 - 396.

L a mmerts W. E., 1934. On the nature of chromosome association in Nicotiana Tabacum haploids. Cytologia, 6, $38-50$.

Meurman O., 1925. The chromosome behaviour in some dioecious plants and their relatives etc. Comment Biol. Helsingf., 2, $1-104$.

Müntzing A., 1937. Polyploidy from twin seedlings. Cytologia, Fuji Jub. Vol. $211-227$.

M ü n t z i n g A., 1938. Note on heteroploid twin plants from eleven genera. Hereditas, $24,487-491$.

M üntzing A., 1940. Further studies on apomixis and sexuality in Poa. Hereditas. $26,115-190$.

Nordenskiöld H., 1953. A genetical study in the mode of segregation in hexaploid Phleum pratense. Hereditas, 39, $469-488$.

$\mathrm{R}$ u n q u i $\mathrm{s}$ E., 1937. Cytologische und morphologische Valeriana-Untersuchungen. Hereditas, 23, $279-286$.

S k a lińs k a M., 1937. Synthesis of hypertetraploid types of Aquilegia. Amer. Nat. $71,610-612$.

Skalińska M., 1947. Polyploidy in Valeriana officinalis Linn. in relation to its ecology and distribution. Journ. Linn. Soc. Botany, 53, $159-186$.

$\mathrm{Sk}$ a li ń s k a M., 1951. Studies in cyto-ecology, geographic distribution and evolution of Valeriana L. Bull. Acad. Pol. des Sciences et des Lettres Sér. B. 1950, $149-175$.

Skovsted A., 1939. Cytological studies in twin plants. Comptes Rend. Lab. Carlsberg, Sér. Phys. 22, $427-445$.

Sprague T. A., 1943. Field studies on Valeriana officinalis Linn. in the Cottswold Hills. Proc. Linn. Soc. London, Sess. 155, $93-104$.

Tod d, B. H., 1942. The cytology of the Valerianaceae with special reference to the status of the British forms of Valeriana officinalis Thesis. Univ. of Durham, 1941 (A preliminary note on this paper in Vasculum, 27 (1942) 26 - 27). 


\section{EXPLANATION OF PLATE I.}

Fig. 15, 16 - Somatic metaphases in root tips of the twin plants: 15 - the hexaploid hybrid $(2 \mathrm{n}=42) ; 16$ - the polyhaploid plant B $(2 \mathrm{n}=28)$. Navashin gentian violet. Magnification c. $1800 \succ$.

Fig. 17-19 - Meiosis in P.M.C's of the hexaploid hybrid 229/3; 17, 18 top distinct bivalents, 18 bottom - two univalents (First Metaphase, side view); 19 polar view of the First Metaphase plate.

Fig. 20-22 - Meiosis in P.M.C's of the polyhaploid twin plant B; 20 - two approximately normal I Metaphase spindles (side view and polar view); 21 - two First Metaphases with univalents (side view). Note the crowding of chromosomes in the plates; 22 - Three P.M.C's at First Telophase surrounded by multinucleate tapetal cells; in the middle P.M.C. one distinct pole with 14 chromosomes. Magnification of Figs $17-22$ c. $1500 \times$.

Fig. 23, 24 - Later stages of pollen development and abortion in the polyhaploid twin plant; 23 - cross-section of a loculus near the top of the anther at the stage in which size differences between the pollen grains begin to appear; the largest grain is bi-nucleate; 24 - Later stage; longitudinal section of a loculus; one giant pollen grain and a group of shrunken small pollen grains.

Fig. 25 - Pollen grains in a young bud of the hexaploid hybrid 229/3 before their abortion. Magnification of Figs $23-25$ c. $400 \times$

The microphotos have been taken with Leitz Makam combined with the Practiflex camera with the use of a Leitz oil immersion lens $\times 100$ and a Leitz periplan eyepiece $\times$ 10. (Figs 15-22) and a Zeiss compensating eyepiece $\times 5$ (Figs. 23-25). 
PLATE I

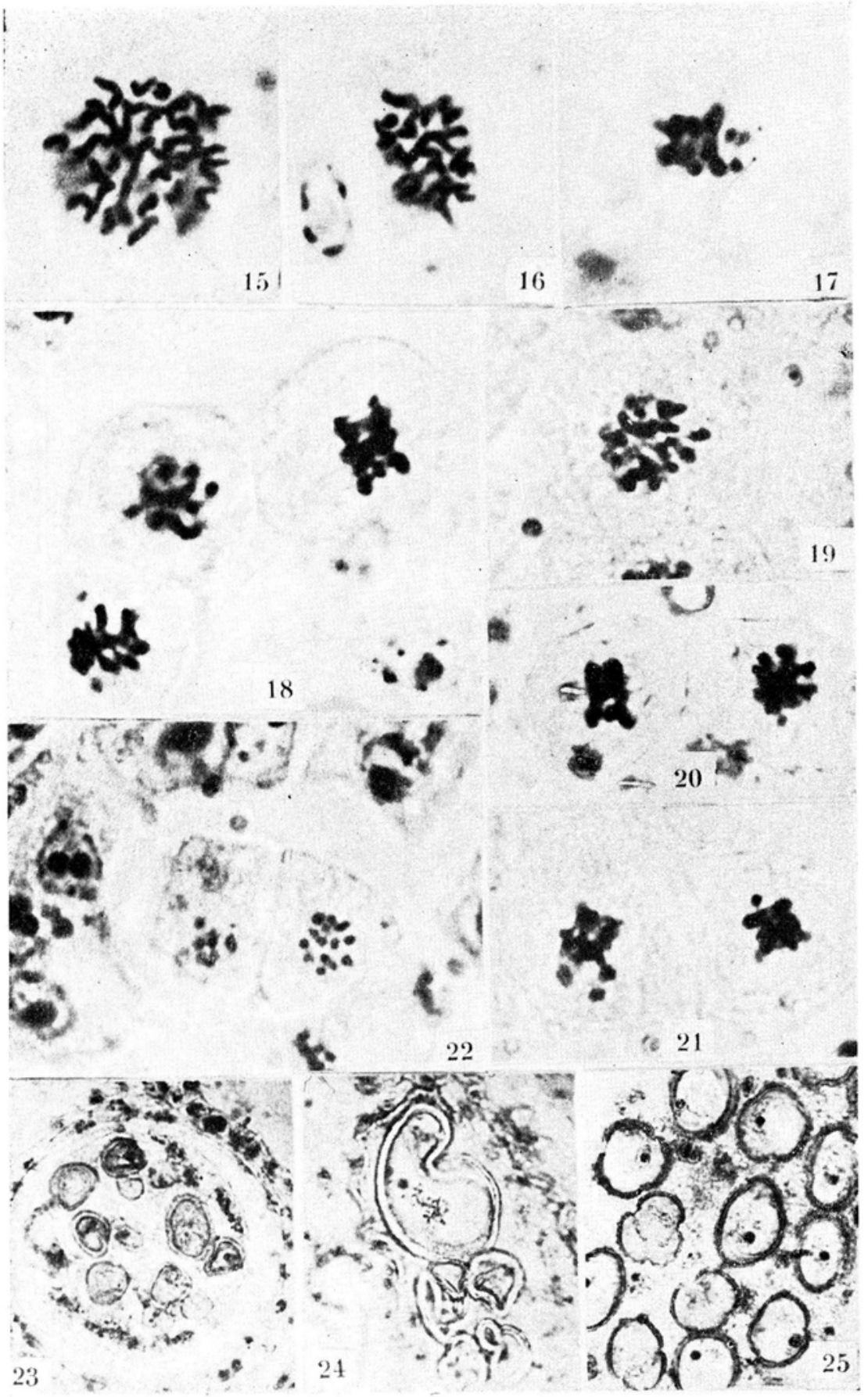

M. Skalinska phot. 